\title{
Gen-Umwelt-Wechselwirkung
}

\section{Ist der Diabetiker das Opfer seiner Gene?}

Bei der Pathogenese des Typ-2-Diabetes sind Erbfaktoren und Umwelt beteiligt. Doch ungünstige Gene sind kein unvermeidbares Schicksal, sondern können durch Änderungen des Lifestyle in ihrer Aktivität gebremst werden. Umgekehrt modulieren Gene den Effekt von lebensdiätetischen Maßnahmen. Diese komplexen Wechselwirkungen könnten neue Wege für eine Therapie des Typ-2-Diabetes ermöglichen.

Der größte diabetogene Effekt unter den Diabetes-Genen wird einem Gen zugeschrieben, welches für die inkretinstimulierte Insulinsekretion verantwortlich ist. Eine Risikovariante dieses Gens führt zu einer Abnahme der Insulinsekretion. Eine Variante im Gen des Fettsäurerezeptors 1 bewirkt ebenfalls eine Störung der Insulinsekretion. Sind die freien Fettsäuren als Folge einer ungesunden Ernährung erhöht, wird dieses Gen stärker aktiviert. Bewegungsarmut und eine proteinreiche Ernährung wiederum stimulieren die Variante eines Gens, welches bei der Bildung des Fettgewebes mitverantwortlich ist.

\section{Keine Einbahnstraße}

Doch die Wechselwirkungen zwischen Genen und Umwelt sind keine Einbahnstraße. „Vielmehr müssen wir davon ausgehen, dass Gene umgekehrt den Effekt von diätetischen Bemühungen bei der Diabetes-Prävention modulieren“, so Dr. Robert Wagner, Tübingen. Lebensstilfaktoren würden durch Gene verstärkt oder abgeschwächt. Während bei dem Einen dadurch das Diabetesrisiko deutlich ver- ringert werde, zeigten diese Bemühungen bei dem Anderen kaum eine Wirkung. So wird z.B. durch eine bestimmte Genvariante der Schutzeffekt einer ballaststoffreichen Ernährung zunichte gemacht. Andererseits können die Träger einer bestimmten Genmutation vor den schädlichen Auswirkungen einer fettreichen Ernährung geschützt sein.

„Inwieweit diese komplexen Wechselwirkungen für die Manifestation des Diabetes wirklich verantwortlich sind, lässt sich schwer beurteilen“, so Wagner. Könnten wir diese Interaktionen genau charakterisieren, wäre dies ein wichtiger Schritt in Richtung auf eine individualisierte Prävention und Therapie. (Peter Stiefelhagen)

Symposium "Gen-Umwelt-Interaktionen", 50. Deutscher Diabeteskongress, Berlin 2015
- folge mit dem Neuropathie-Defizit-Score bewertet werden. Zudem sind Hinweise auf eine autonome Neuropathie zu beachten. Versorgt mindestens eine Arterie den Fuß ohne relevante Strömungsbehinderung, kann man von dessen ausreichender arterieller Durchblutung ausgehen.

\section{Vorbereitende Sanierung des Wundbettes}

Zur Wundreinigung werden abgestorbene Gewebeanteile möglichst beseitigt. Trockene Nekrosen können meist von den mit einem Skalpell gelösten Rändern her entfernt werden. Bestehen tiefe Wundhöhlen und Fistelgänge, kann mit einem scharfen Löffel kürretiert werden. Um den Abfluss des eitrigen Wundsekrets zu gewährleisten, ist eine Gegeninzision am tiefsten Pol solcher Gänge hilfreich. Bei gangränösen Infektionen müssen solche Prozeduren mehrmals täglich stattfinden. Je nachdem, ob eine Neuropathie mit gleichzeitiger Durchblutungsstörung und ausgeprägter Hyperpathie oder ausschließlich eine Neuropathie vorliegen, ist hierbei eine Anästhesie erforderlich oder nicht. Das Wunddébride- ment ist wichtig für die Wirksamkeit der weiteren Behandlungsmaßnahmen.

Im Anschluss an das Débridement wird standardmäßig ein tiefer Abstrich zur mikrobiologischen Diagnostik durchgeführt. Bei Verdacht auf eine Osteomyelitis kann eine Knochenbiopsie das Keimspektrum im Knochen aufdecken.

\section{Therapeutische Maßnahmen}

Die Lokalbehandlung muss der jeweiligen Wundsituation angepasst werden. Weist die gereinigte Wunde keine Infektionszeichen auf, ist eine feuchte Wundbehandlung indiziert. Entscheidend für die Auswahl der Wundauflage ist dabei die Sekretionsstärke. Bei bradytrophem Gewebe und geringer Wundsekretion sind Hydrokolloidverbände geeignet, da sie im Vergleich zum Polyurethanschaum weniger Sekret binden und die Wunde feuchter halten. Befindet sich die Wunde dagegen in einem frühen Stadium und besteht ein Umgebungsödem, ist mit reichlich Sekret zu rechnen, und es sollten Alginat- und Polyurethanschaumauflagen gewählt werden.

Ist die Wunde infiziert, muss zum Débridement ein Antiseptikum appliziert werden. Zudem soll bei deutlichen Zeichen einer Infektion wie Rötung, Ödem und eitrigem Sekret sofort, ohne den mikrobiologischen Befund abzuwarten, eine Lokaltherapie mit einem Antibiotikum begonnen werden, so Raabe.

Als Therapeutika stehen hier Cephalexin und Clindamycin an erster Stelle. Bei schweren Infektionen wird häufig gleich zu Beginn eine Kombination von Amoxicillin/Clavulansäure oder Clindamycin mit Ciprofloxacin eingesetzt. Bestehen systemische Infektzeichen, kann eine parenterale Therapie erforderlich sein.

Wesentlich für die Wundheilung ist zudem eine ausreichende Druckentlastung. Sie ist beispielsweise möglich durch Orthesen mit Weichpolsterauflage, Gipstechnik, therapeutische Schuhe oder das Benutzen von Gehstützen bzw. Rollstuhl.

(Christine Starostzik)

Raabe J. Erstversorgung von Menschen mit einem diabetischen Fußsyndrom. Diabetologe 2015, 11:123-129; Morbach S et al. Praxisempfehlungen der Deutschen Diabetes Gesellschaft 2012;

NVL Typ-2-Diabetes 2010, derzeit in Überarbeitung 